\title{
ACHADOS ANATOMOPATOLÓGICOS DE Toxoplasma gondii EM Lagothrix lagotricha DA REGIÃO AMAZÔNICA BRASILEIRA
}

\author{
Lucien Roberta Valente Miranda de Aguirra $^{1}$ \\ Marcella Katheryne Marques Bernal ${ }^{1}$ \\ Washington Luiz Assunção Pereira ${ }^{2}$
}

\begin{abstract}
RESUMO
O Toxoplasma gondii é um coccídeo zoonótico e cosmopolita, com transmissão horizontal e vertical, e ciclo biológico do tipo heteroxênico, capaz de infectar uma ampla variedade de animais homeotérmicos, incluindo primatas não-humanos e humanos. A evolução desta enfermidade se manifesta de forma aguda e crônica, dependendo da relação parasitohospedeiro, condição fisiológica do infectado e virulência, podendo levar ao óbito. Neste relato, foram realizadas necropsias de três espécimes de Lagothrix lagotricha, sendo observado edema pulmonar e aumento no tamanho dos linfonodos mesentéricos e submandibulares, assim como hepatoesplenomegalia. Amostras de diferentes tecidos foram colhidas e fixadas em formol a $10 \%$ tamponado, processadas e analisadas. Por meio da histopatologia foram identificadas estruturas do T. gondii nas formas de cistos nos tecidos de linfonodos, musculatura cardíaca, pulmões, baço e fígado e taquizoítos no tecido hepático. Assim, pode-se concluir que que este relato contribui para o conhecimento sobre a infecção por T. gondii em primatas não-humanos, considerando a possibilidade de continuidade do ciclo no ecossistema amazônico, pela observância das formas do coccídeo em diversos tecidos de L. lagotricha, sem desenvolver as alterações macroscópicas caraterísticas.
\end{abstract}

Palavras-chave: primata neotropical, coccídeo, histopatologia, ecossistema amazônico.

\section{ANATOMOPATHOLOGICAL FINDINGS OF Toxoplasma gondii IN Lagothrix lagotricha FROM THE BRAZILIAN AMAZON REGION}

\section{SUMMARY}

Toxoplasma gondii is a zoonotic and cosmopolitan coccid, with horizontal and vertical transmission, and a biological cycle of the heteroxenic type, capable of infecting a wide variety of homeothermic animals, including non-human primates and human. The evolution of this disease manifests itself in an acute and chronic form, depending on the parasite-host relationship, the physiological condition of the infected and virulence, which can lead to death. In this report, necrpsies of three specimens of Lagothrix lagotricha was performed. In the necroscopic examination of the specimens, pulmonary edema and an increase in the size of the mesenteric and submandibular lymph nodes, as well as hepatosplenomegaly. Samples from diferente tissues were collected and fixed in $10 \%$ buffered formaldehyde, processed and analyzed. Through histopathology, structures of of $T$. gondii were identified in the forms of cystzoites in lymph node tissues, cardiac musculature, lungs, spleen and liver, and tachyzoites in liver tissue. Thus, it can be concluded that this report contributes to the knowledge about the infection by $T$. gondii in non human primates, considering the possibility of continuity of

\footnotetext{
${ }^{1}$ Doutorando na Universidade Federal Rural da Amazônia Correspondência: lucyaguirra@yahoo.com.br

${ }^{2}$ Professor Titular Universidade Federal Rural da Amazônia
} 
the cycle in the Amazonian ecosystem, by observing the forms of the coccid in several tissues of L. lagotricha, without developing macroscopic changes characteristics.

Keywords: neotropical primate, coccid, histopathology, amazonian ecosystem.

\title{
HALLAZGOS ANATOMOPATOLOGICOS DE Toxoplasma gondii EN Lagothrix lagotricha DE LA REGIÓN DE LA AMAZONIA BRASILEÑA
}

\begin{abstract}
RESUMEN
Toxoplasma gondii es un coccidio zoonótico y cosmopolita, con transmisión horizontal y vertical, y el ciclo biológico de tipo heteroxenico, capaz de infectar una amplia variedad de animales homeotérmicos, incluidos primatas no humanos y humanos. La evolución de esta enfermedad se manifesta de forma aguda y crónica, dependiendo de la relación parásitohuésped, la condición fisiológica del infectado y la virulencia, que puede conducir a la muerte. En este informe se realizó la necropsia de tres especímenes de Lagothrix lagotricha, com edema pulmonar y aumento del tamaño de los ganglios linfáticos mesentéricos y submandibulares, así como hepatoesplenomegalia. Se recolectaron muestras de diferentes tejidos y se fijaron en formaldehído tamponado al $10 \%$, se procesaron y analizaron. Mediante histopatología, se identificaron estructuras de $T$. gondii en forma de cistos en tejidos de ganglios linfáticos, musculatura cardíaca, pulmones, bazo y hígado, y taquizoítos en el tejido hepático. Así, se pudo concluir que este informe contribuye con conocimiento sobre la infección por $T$. gondii en primatas no humanos, considerando la posibilidad de continuidad del ciclo en el ecosistema amazónico, al observar las formas del coccidio en varios tejidos de L. lagotricha, sin desarrollar los cambios macroscópicos característicos.
\end{abstract}

Palabras-clave: primata neotropical, coccidio, histopatología, ecosistema amazónico.

\section{RELATO DE CASO}

A pesquisa foi aprovada pelo SISBIO (licença $N^{\circ} 39285$ ) e pelo Comitê de Ética no Uso de Animais da Universidade Federal Rural da Amazônia sob o n ${ }^{\circ}$ 034/2014/CEUA 23084.022512/2014-18/UFRA.

Necropsias de três espécimes machos de Lagothrix lagotricha oriundos de doação de animais silvestres para o um criatório conservacionista em região de floresta amazônica, situado no Estado do Pará, Brasil, que recebe e abriga animais oriundos de apreensão. Como os animais não possuíam histórico clínico, a necropsia foi realizada de forma completa, seguindo as especificações descritas por Peleteiro (1).

No exame necroscópico foi observado ausência de colapso pulmonar e presença de edema em todos os espécimes analisados (Figura 1A). Ao corte, o tecido exibia extravasamento de líquido de aspecto espumoso, que se estendia até a traqueia. Os linfonodos mesentéricos (Figura 1B) e submandibulares estavam aumentados de tamanho, bem como fígado e baço. Os demais órgãos não demonstraram alterações macroscópicas dignas de notas. 


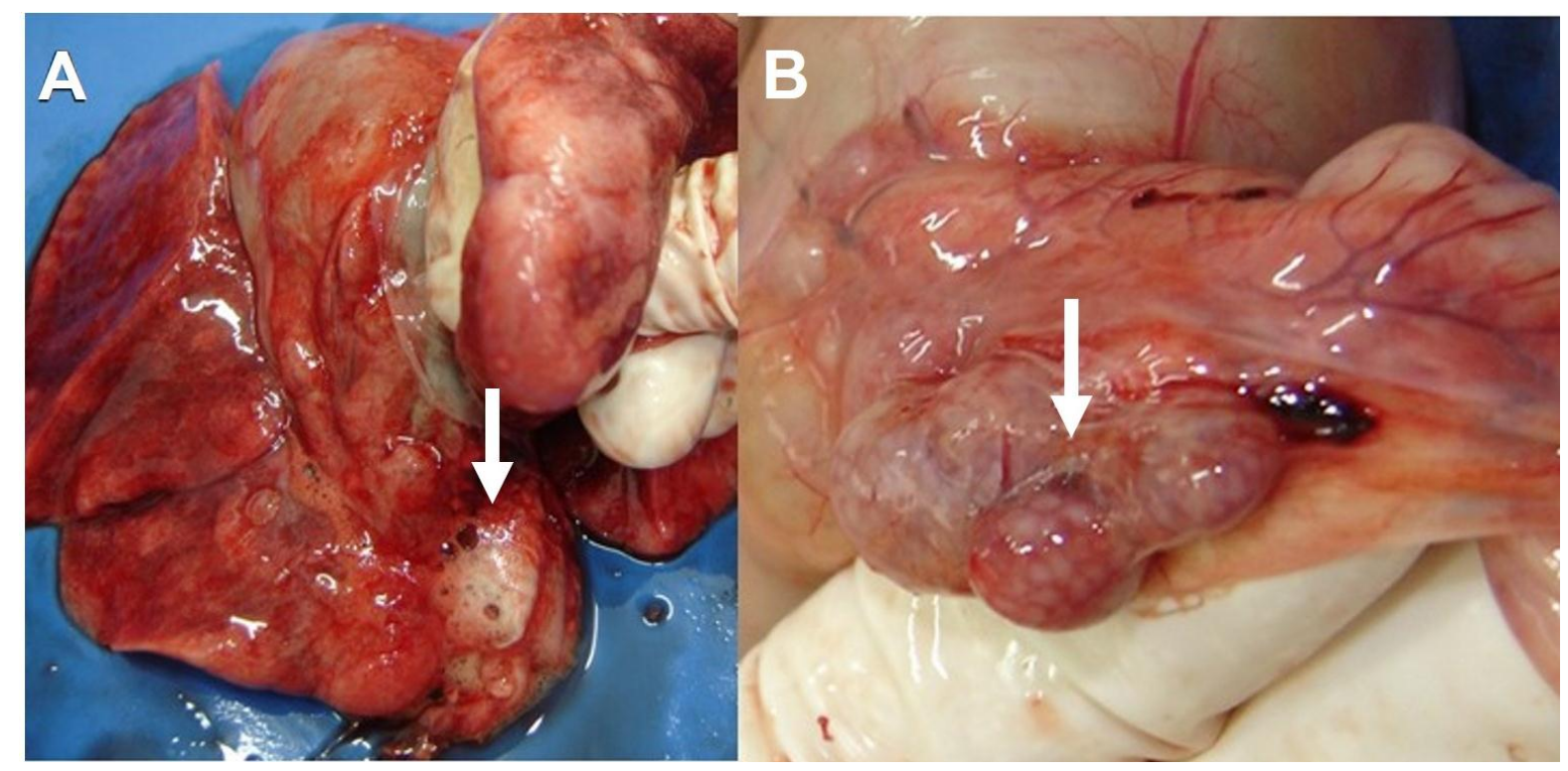

Figura 1. Exame necroscópico de Lagothrix lagotricha. A - Pulmão edemaciado, com extravasamento de líquido de aspecto espumoso, ao corte (seta). B - Linfonodos mesentéricos aumentados de tamanho (seta).

Amostras dos tecidos que exibiram alterações, assim como musculatura cardíaca e rins foram colhidas e fixadas em formol a $10 \%$ tamponado. Posteriormente, fragmentos foram clivados e submetidos a processamento pela técnica histológica de rotina para inclusão, corte em parafina e obtenção de lâminas histológicas coradas por hematoxilina-eosina segundo a técnica descrita por Tolosa et al. (2). As lâminas foram avaliadas em microscópio óptico (DI136T LED) nos aumentos de 20x, 40x e 100x.

Pelo exame histopatológico foi notada a presença de estruturas de $T$. gondii nos aumentos de 40x e 100x em microscopia de luz, evidenciando a presença de cistos nos tecidos de linfonodos (Figura 2), musculatura cardíaca, pulmões, baço e fígado. Neste último, também foram identificadas a forma evolutiva de taquizoítos.

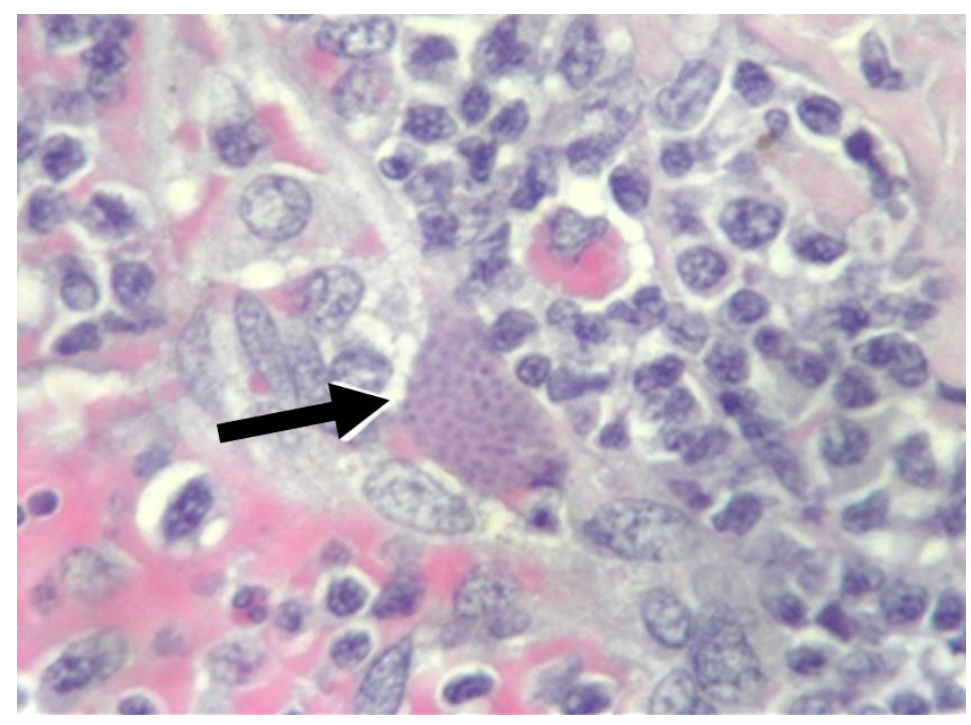

Figura 2. Fotomicrografia de linfonodo de Lagothrix lagotricha exibindo cistozoíto de toxoplasmose (seta), HE, aumento 40x. 
O T. gondii é amplamente estudado por possuir caráter zoonótico e assumir uma configuração epidemiológica de distribuição mundial, detendo a capacidade de parasitar uma ampla variedade de animais homeotérmicos, incluindo primatas não-humanos ( $\mathrm{PNH})$ e humanos $(3,4)$. De modo que a descrição dos achados anatomopatológicos em três espécimes de L. lagotricha amplia o conhecimento sobre o tema, uma vez que demonstra a possibilidade de continuidade do ciclo deste coccídeo no ecossistema da região amazônica e sua transmissão horizontal.

Esse coccídeo é do tipo intracelular obrigatório, com transmissão horizontal e vertical (5) e ciclo biológico heteroxênico, com reprodução assexuada nas células de hospedeiro intermediário (incluindo anfíbios, mamíferos, répteis e aves) e sexuada nas células epiteliais do intestino de felídeos (6). A evolução da enfermidade acontece de forma aguda e crônica, dependendo da relação parasito-hospedeiro, condição fisiológica do infectado e virulência, com episódios eventualmente fatais $(4,7)$. No Brasil, Grumann et al. (8) descreveram que a toxoplasmose é responsável pelo aumento de óbitos em PNH neotropicais de vida livre e cativos.

As lesões desencadeadas, independente da espécie hospedeiro, são similares e o que as diferencia é a localização parasitária, pelo seu caráter intracelular, podendo afetar diversos sistemas como o nervoso, muscular, linfático, ocular ou placentário, entre outros $(9,10)$. Tal fato foi observado nos espécimes deste relato, sendo identificados cistos em linfonodos, musculatura cardíaca, pulmões, baço e fígado, além de formas taquizoítas no fígado. Ademais, nos três espécimes de L. lagotricha foi observado linfadenopatia, hepatomegalia e esplenomegalia, o que segundo alguns autores, são alterações frequentemente observadas nos casos de infecção por $T$. gondii $(10,12)$.

Em geral, as pesquisas realizadas utilizam técnicas sorológicas para determinar a presença de anticorpos anti- $T$. gondii em animais, a exemplo de Minervino et al. (13), que pesquisou o coccídeo em PNH da região Amazônica, obtendo resultados positivos em 49,2\% dos animais. Contudo, a histopatologia e a imuno-histoquímica, tem sido bastante utilizada em animais, especialmente silvestres e de produção, por permitir a identificação de taquizoítos na fase aguda ou cistos teciduais na fase crônica $(4,14)$. Os tecidos que exibem maiores chances de identificação do coccídeo são os que apresentam macroscopicamente focos necróticos puntiformes (4). Contudo, nos três espécimes avaliados neste relato, tal alteração não foi observada, o que demonstra que pode ser possível a observância das formas do $T$. gondii sem que haja a presença de alteração macroscópica característica.

Ao analisar a diversidade de espécies existentes na região amazônica, este relato contribui para o conhecimento sobre a infecção por $T$. gondii em $\mathrm{PNH}$, considerando a possibilidade de continuidade do ciclo no ecossistema amazônico, pela observância das formas do coccídeo em diversos tecidos de L. lagotricha, sem desenvolver as alterações macroscópicas caraterísticas.

\section{REFERÊNCIAS}

1. Peleteiro MC. Manual de necrópsia veterinária. São Paulo: Lidel; 2016.

2. Tolosa EMC, Behmer AO, Freitas-Neto AG. Manual de técnicas para histologia normal e patológica. São Paulo: Manole; 2003.

3. Jones TC, Hunt RD, King NW. Patologia veterinária. São Paulo: Manole; 2000.

4. Dubey JP. Toxoplasmosis of animals and humans. Boca Raton: CRC Press; 2010. 
5. Lindsay DS, Dubey JP. Toxoplasmosis in wild and domestic animals. In: Weiss L, Kami KA. Toxoplasma gondii: the model apicomplexan perspectives and methods. London: Academic Press; 2007. p.133-52.

6. Neves DP. Parasitologia dinâmica. São Paulo: Atheneu; 2003.

7. Peláez CC, Claudia PRT, Salas-Garrido CG, Correa D. Acute toxoplasmosis in squirrel monkeys (Saimiri scirieus) in Mexico. Vet Parasitol. 2011;180(3-4):368-71. doi: 10.1016/j.vetpar.2011.03.012.

8. Grumann MR, Silva Z, Silva Filho JR, Costa MM, Vieira MIB, Motta AC. Immunohistochemical and serological aspects of Toxoplasma gondii infection in neotropical. Semina Cienc Agrar. 2017;38(3):1375-82. doi: 10.5433/16790359.2017v38n3p1375.

9. Corrêa WM, Corrêa CNM. Enfermidades infecciosas dos mamíferos domésticos. Rio de Janeiro: Medsi; 1992.

10. Dubey JP, Lappin MR. Toxoplasmosis and neosporosis. In: Greene CE. Infectious diseases of the dog and cat. St. Louis: Saunders Elsevier; 2006. p.754- 75.

11. Bresciani KDS, Toniollo GH, Costa AJ, Sabatini GA, Moraes FR. Clinical parasitological and obstetric observation in pregnants bitches with experimental toxoplasmosis. Cienc Rural. 2001;31(6):1039-43. doi: 10.1590/S010384782001000600020 .

12. Casagrande RA, Silva TCE, Pescador CA, Borelli V, Souza JC Jr, Souza ER, et al. Toxoplasmose em primatas neotropicais: estudo retrospectivo de sete casos. Pesqui Vet Bras. 2013;33(1):94-8. doi: 10.1590/S0100-736X2013000100017.

13. Minervino AHH, Cassinelli ABM, Souza AJS, Alves MM, Soares MCP, Ferreira DAC, et al. Detection of Toxoplasma gondii antibodies in captive non-human primates in the Amazon region, Brazil. J Med Primatol. 2017;46(6):343-6. doi: 10.1111/jmp.12314.

14. Hill DE, Dubey JP. Toxoplasma gondii: transmission, diagnosis and prevention. Clin Microbiol Infect. 2002;8(10):634-40. doi: 10.1046/j.1469-0691.2002.00485.x.

Recebido em: 15/12/2020 Aceito em: 15/03/2021 